\title{
Using risk assessment to guide progressive closure planning for the Ok Tedi Mine
}

\author{
S. Mackenzie Mine Earth Pty Ltd, Australia
}

A. Topurua Ok Tedi Mining Limited, Papua New Guinea

M. Werror Ok Tedi Mining Limited, Papua New Guinea

\begin{abstract}
The Ok Tedi mine is located in the Western Province of Papua New Guinea (PNG) and is owned and operated by Ok Tedi Mining Limited (OTML), a company that is entirely owned for the benefit of the people of PNG. Since mining commenced in 1984, OTML has been the foremost contributor to the economy of the PNG. Under the current mine plan, ore reserves will be mined out by 2015; however opportunities are being investigated to extend the mine life to 2025. OTML have been actively planning for closure since 1998 and aims to make the closure of OK Tedi an example of good practice.
\end{abstract}

OTML have adopted a risk based approach to guide the closure planning process that aligns with the Australian and New Zealand Risk Management Standard (AS/NZ 31000:2009). Mine closure risks have been identified in open, facilitated workshops attended by a broad range of internal and external stakeholders. Two broad categories of closure risks have been identified: OTML risks and residual risks. OTML risks are the responsibility of OTML and residual risks are not necessarily the responsibility of OTML and may remain after closure.

OTML risks were carried forward for quantification and risk modelling. The risk model allowed OTML to estimate pre-mitigation risk cost and develop an optimal risk mitigation strategy in order to reduce the risk cost. From the risk model OTML has included within their closure cost estimate a risk mitigation allowance and a risk based contingency provision.

Irrespective of who owns residual risks, they remain risks to the closure process. The stakeholder group responsible for closure planning for Ok Tedi agreed that residual risks need to be assigned a risk owner(s). OTML has coordinated stakeholder workshops to explore the residual risks and to discuss the risks in the context of possible mitigation strategies and responsibilities. OTML will continue to assist stakeholders to work through and plan for residual risks.

One outcome of the residual risk assessment process was that the stakeholder group agreed to jointly support a study to investigate the social impacts that will result from predicted flooding caused by mine derived sediments. The study also aims to define strategies to alleviate long term impacts, and assess what role stakeholders may play in implementing these strategies.

The outcomes of the risk assessment have also supported other good practice closure planning initiatives including: open engagement of stakeholders in closure planning; developing post closure and relinquishment plans; a detailed investigation into the social and economic impacts of closure; and defining closure costs to the satisfaction of independent auditors.

\section{Introduction}

The Ok Tedi mine is located in the upper catchment of the Fly River System in the Western Province of Papua New Guinea (PNG) (Figure 1). The mine is a world class producer of copper and gold, and is owned and operated by OTML. Mining commenced at Ok Tedi in 1984 and under the current mine plan, ore 
reserves will be mined out by 2015 . Genuine opportunities are currently being investigated to extend the mine life to 2025.

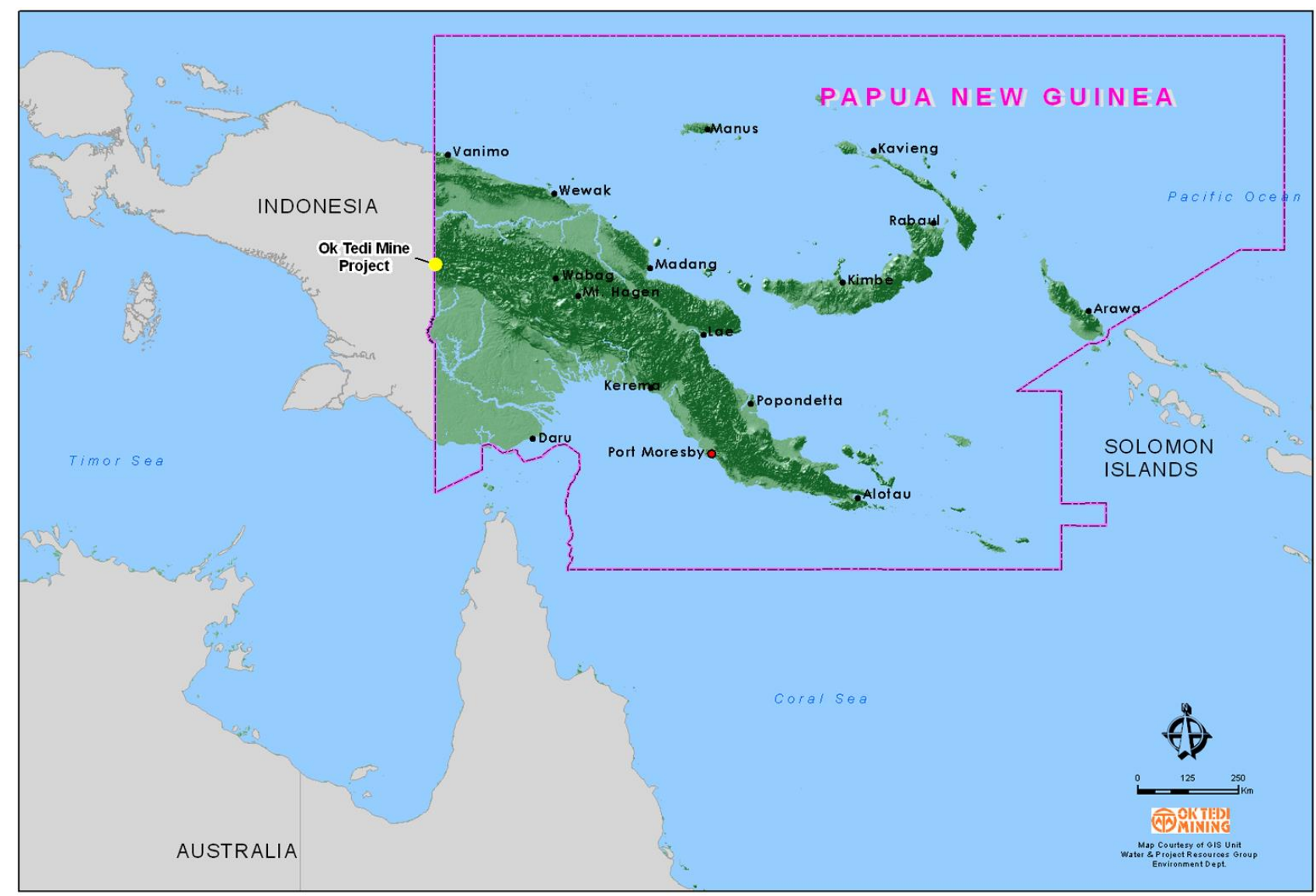

\section{Figure 1 The Ok Tedi mine is located in the Western Province of PNG}

\subsection{Project description}

The Ok Tedi project consists of a number of operational areas including the mine, the mill, Tabubil, Bige and Kiunga (Figure 2). Ore is mined from the open pit and transferred to the mill for processing. Waste rock from the mine and tailings from the mill are discharged into the Ok Tedi River. Copper concentrate is piped from the mill to Kiunga where it is dried and loaded onto barges for transport down the Fly River.

Concentrate is transferred from the barges onto a transhipment vessel (M.V. Erawan) which is anchored either in the Gulf of Papua or in Port Moresby Harbour depending on weather conditions. Concentrate is off-loaded from the Erawan to export vessels for transport to markets around the world.

A dredge operates in the Ok Tedi at Bige to extract mine derived sediment from the river. These sediments are deposited on both the east and west banks of the Ok Tedi and are reworked into stable stockpiles. Pyrite concentrate is separated from tailings at the mill and is piped to Bige for subaqueous storage under the West Bank Stockpile.

The majority of the Ok Tedi workforce lives in the township of Tabubil which has a population of approximately 10,000. OTML also have offices in Port Moresby, Kiunga and Brisbane, Australia.

\subsubsection{Location and climate}

The Ok Tedi mine is located close to the headwaters of the Ok Tedi, approximately 1,000 river kilometres from the coast. Regional elevations reach 3,500 m above sea level. The Fly River system has a catchment area of about $75,000 \mathrm{~km}^{2}$ and comprises three main tributaries: the Ok Tedi; the Upper Fly; and the 
Strickland (Pickup, 2009). The Ok Tedi receives waste rock and tailings from the Ok Tedi mine and the Strickland receives sediment from mining operations at Porgera.

The Fly basin has a humid tropical climate and average rainfall varies with elevation (Moi et al., 2001). Rainfall excess of 10,000 mm/year occur at the Ok Tedi mine site (1,500-2,000 masl) and decline to about $8,000 \mathrm{~mm} /$ year along the upper and middle Ok Tedi.

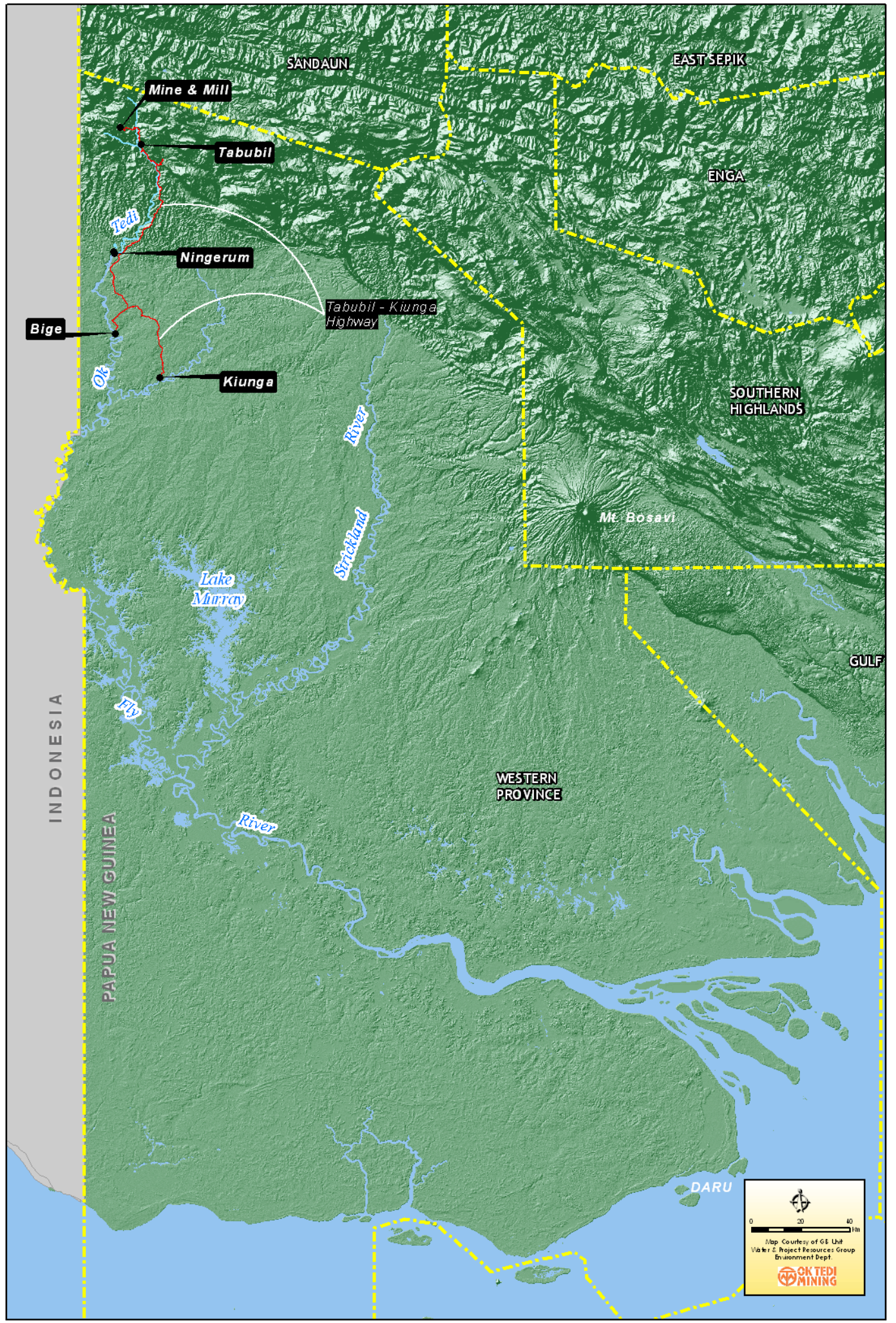

Figure 2 The Ok Tedi project site in relation to the Western Province 


\subsubsection{Mine affected geomorphology}

Up to 80 million tonnes of waste rock and tailings have been discharged annually from the Ok Tedi mine into the Ok Tedi /Fly River system. The original mine design incorporated a tailings dam, but its foundations collapsed in a landslide during construction in 1984 (Swales et al., 2000; Storey et al., 2009). Subsequently, State approval was granted for tailings to be discharged directly to the river system.

The impacts to the river system from mine waste disposal are mostly physical impacts associated with aggradation. Prior to mining, the natural sediment load of the Ok Tedi was 3-5 Mt/year (a similar load to the Upper Fly) (Higgins et al., 1987). Between 1985 and 2000, the load in the Ok Tedi increased to an average $45 \mathrm{Mt} /$ year as a result of waste rock and tailings deposition (Pickup, 2009). Some reaches of the river have experienced extensive deposition, raising the riverbed, adding material to levees and flood plains, and increasing the duration and frequency of flood plain inundation.

Following regular monitoring by OTML and a comprehensive three year Community Health Survey conducted from 2003 to 2006 (Bentley, 2007a; 2007b) it was found that there are no mine-related human health issues regarding the edibility of foodstuffs throughout the system. This includes drinking and recreational waters, air quality, and all aquatic and terrestrial flora and fauna.

The dredging operation at Bige will continue to the end of mine life and will assist in minimising future physical impacts.

\subsection{Ownership structure and benefits}

The structure of OTML is unique in that the company is owned $100 \%$ for the benefit of the people of PNG. The shareholders of OTML include the Independent State of PNG (the State) (36.6\%) and PNG Sustainable Development Program Limited (PNGSDP) (63.4\%). The State allocates half of the dividends it receives (18.3\% of total dividends) into trust funds for the Fly River Provincial Government, mine area landowners and the people of Western Province.

PNGSDP were established as a trust fund to support sustainable development in PNG, particularly in the Western Province. PNGSDP acquired equity in OTML as part of BHP Billiton's exit strategy in 2002. The Ok Tedi mine produced environmental consequences that were unacceptable to BHP and international observers, and BHP elected to close the mine in 2000. The State and the communities however agreed that the economic benefits of continuing the mine outweighed the environmental impacts. These were the circumstances which lead to the establishment of PNGSDP.

Since production commenced in 1984 OTML has been the foremost contributor to the economy of PNG and has delivered over US\$ 11 billion through taxes, royalty payments, dividends, compensation and wages. In 2011 OTML paid US\$ 685 million in dividends to shareholders, US\$ 494 million in taxes and US\$ 60 million in compensation, royalties and land lease payments. Considerable wealth has been generated and delivered by OTML to its shareholders and OTML assists with the management of the wealth it generates through a number of avenues.

\subsection{Legal framework and closure planning history}

The Mining (Ok Tedi Agreement) Act 1976, otherwise known as the Principal Agreement, applies to OTML and its operations. There have been amendments to the Principal Agreement on nine occasions.

The Mining (Ok Tedi Mine Continuation (Ninth Supplemental) Agreement) Act 2001 was enacted by the National Parliament on 20 December 2001, to allow BHP Billiton to exit from the Ok Tedi project in February 2002. The Ok Tedi Mine Closure and Decommissioning Code 2001 (Code) was included as a schedule to the Ninth Supplemental Agreement and is the principal guide for closure planning at Ok Tedi.

The Code provides a statutory regime to plan for closure. In accordance with the Code OTML have submitted draft mine closure plans in 2002, 2004 and 2006, and a detailed mine closure plan in 2009 four 
years prior to the expected date of mine closure. The 2009 Plan met and in many instances exceeded the requirements of the Code, and was approved by the State of PNG in May 2012.

Prior to the enactment of the Code, formal mine closure planning commenced at Ok Tedi in 1998 with stakeholder engagement and the subsequent development of a Conceptual Rehabilitation and Closure Plan. Stakeholder consultation continued and in 2000 OTML submitted a Rehabilitation and Closure Plan, along with a report on social and sustainable development issues, to the State.

\section{$2 \quad$ Mine closure risk assessment}

OTML have adopted a risk based approach to mine closure planning that aligns with the Australian and New Zealand Risk Management Standard (AS/NZ 31000:2009). The mine closure risk assessment process for Ok Tedi has included risk identification with internal and external stakeholders, and risk quantification and risk modelling of OTML risks.

\subsection{Risk identification}

The mine closure risk assessment commenced with a two day risk identification workshop. The workshop was facilitated by an external specialist and was attended by a large group of internal and external stakeholders, including:

- PNGSDP.

- Fly River Provincial Government.

- PNG National Government.

- Independent closure cost auditors appointed on behalf of the State.

- Landowner representatives.

- OTML management and staff.

During workshop deliberations no boundaries were imposed on risk identification other than restricting discussions to mine closure. This resulted in a wide range of closure risks being identified including, inevitably, risks to parties other than OTML.

Workshop outcomes were consolidated into a risk register, the register divided risks into 'OTML' and 'residual' risks. OTML risks are the responsibility of OTML and residual risks are not necessarily the responsibility of OTML and may remain after closure.

\subsection{Risk quantification and modelling}

Twenty OTML risks from the risk register were carried forward for quantification which involved determination of likelihood, consequence and mitigation actions by an expert panel. This information was then processed through a financial model using the RISQUE method (Bowben et al., 2001) to: develop a risk profile to rank closure risks; develop an exposure profile and determine the costs associated with risk events; assess the cost-effectiveness of risk mitigation actions and develop a preferred mitigation strategy; and provide a risk-based contingency for inclusion in the closure cost estimate.

Risk modelling determined that the pre-mitigation risk profile was dominated by four key risk events. The risk quotients for the four highest-risk events were greater than the cut-off value adopted for the 'threshold method' of calculating the risk cost. Risk modelling demonstrated that the four highest-risk events had relatively low to moderate occurrence costs and that without implementing any risk mitigation actions the pre-mitigation risk cost was US\$ 24.6 million.

The cost of implementing combinations of mitigation actions was assessed against the impact on the premitigation risk cost, in order to develop an optimal mitigation strategy. The optimal strategy for Ok Tedi involved the implementation of mitigation for the four highest-risk events in the risk profile. The 
implementation of these four mitigation actions reduced the total risk cost from US\$ 24.6 to 4.7 million. The cost to mitigate these risks was estimated to be an additional US\$ 4.1 million.

As a result of the mine closure risk assessment both the recommended risk mitigation strategy and the recommended risk-based contingency allowance were endorsed by the OTML Board.

\section{Integration of risk outcomes}

Risk assessment outcomes have been integrated into the closure planning process to help define and prioritise closure planning initiatives. The risk assessment process has provided the impetus for OTML and their stakeholders to consider:

- The roles and responsibilities of stakeholders in managing residual risks.

- Relations with stakeholders in planning for closure.

- Planning for the post closure period.

- The social and economic impacts of closure.

- The costs required to fund closure.

Each of these is discussed in further detail below.

\subsection{Stakeholders and residual risk}

Residual risks will remain after closure and are not necessarily the responsibility of OTML. Irrespective of who owns residual risks, they remain risks to the closure process. The stakeholder group involved in closure planning for Ok Tedi determined that residual risks need to be assigned a risk owner(s) and have an appropriate mitigation strategy.

To assist stakeholders to prepare for closure OTML has coordinated stakeholder workshops to explore the residual risks and to discuss the risks in the context of mitigation strategies and responsibilities. OTML will continue to assist stakeholders to work through and plan for residual risks.

\subsubsection{Riverine social impact assessment}

One outcome from the residual risk assessment process was that the stakeholder group have agreed to jointly support a study is to investigate the social impacts at the village scale that will result from predicted flooding caused by mine derived sediment. The project also aims to define strategies to alleviate long term impacts, and assess what role stakeholders may play in implementing these strategies. PNGSDP are leading the study in close collaboration with the stakeholder group.

A vast amount of work has been (and continues to be) undertaken in order to assess the environmental impacts from riverine aggradation. The riverine social impact assessment will rely upon existing topographical and inundation information to help determine what the flooding regime will be over time in various regions. It is proposed that this information be coupled with land use mapping information (hunting, fishing, sago, gardening and housing patterns), and perhaps more detailed topographical information, for a range of communities to help quantify the social impacts of changed inundation patterns that will occur over time.

\subsection{Stakeholder relations}

Stakeholders play an important role in mine closure planning and they often have a long term interest in an area beyond the operating phase of a mine. Ok Tedi has had both positive and negative impacts on stakeholders, and some of these impacts will continue after mine closure. The risk of not consulting with stakeholders during the closure planning process was the fifth highest risk on the modelled risk profile. 
Closure planning at Ok Tedi has been undertaken through close and ongoing consultation with stakeholders, and with a high level of transparency via: direct engagement of primary stakeholders in the closure planning process; consultation with those communities who will be impacted by mine closure; and general communication to a broader range of stakeholders.

\subsubsection{Direct engagement}

Primary stakeholders are directly engaged in closure planning for Ok Tedi. In 2008 OTML and their stakeholders agreed on an approach to enable stakeholders to be engaged in all levels of the closure planning process. This agreement was reached in a workshop attended by representatives from a diverse range of stakeholder groups including:

- Various National Government departments.

- The Provincial Government.

- The Local Level Government.

- Landowners and impacted communities.

- PNGSDP.

- Landowner business association.

- The Ok Tedi Mining and Allied Workers Union.

A three tier planning and engagement structure, including stakeholder representation, was defined and endorsed by all workshop attendees. The engagement structure consisted of a high level 'Steering Committee', a 'Planning Committee' and three 'Working Groups'. The terms-of-reference for each tier of the engagement structure were drafted and endorsed by the Planning Committee. OTML have successfully implemented the agreed structure which involves regular meetings. The process of engaging stakeholders is ongoing.

\subsubsection{Community consultation}

OTML consult with those communities who will be impacted by mine closure. There are 17 communities whose land has been occupied by the mine and will be affected by closure activities. The aim of the consultation has been to: provide a general update on the mine closure planning process; discuss post closure land use expectations; provide detailed information on plans for decommissioning and rehabilitation in areas that affect the community; and provide feedback on the items they raised during the previous consultation.

The meetings are coordinated by the OTML Community Relations Department whose officers' visit each of the 17 villages, in addition to the 156 mine impacted communities (with a total population of over 100,000 people), once every six months. OTML notify the communities in advance so they can ensure they are adequately represented at the time of the meetings. Men, women and children are present during meetings which generally lasted between 3-5 hours. Community members participate actively and openly, male community leaders generally lead the discussions on behalf of the community.

National, Provincial and Local Government representatives, as well as representatives from PNGSDP are invited to participate in the community consultation, so they can hear firsthand the issues and concerns being expressed by communities. OTML will continue to visit communities to work toward developing agreed land use objectives for disturbed sites and to resolve community concerns about closure.

\subsubsection{Communication}

In 2008 a strategy was designed to enable mine closure messages to be communicated to a broad range of stakeholders using various communication tools. The strategy has targeted: employees, contractors and their dependants; mine impacted communities; the National and Provincial Government; settlers in the 
mine area villages; non-government organisations; and the general public. The communication strategy has been progressively implemented using communication tools including presentations, workshops, conferences, local radio, intranet, email, community consultation patrols, and national media including news print and television.

\subsection{Post closure and relinquishment planning}

The risk of inadequate post closure planning is that closure risks may not be reduced sufficiently and closure performance may not be adequately measured and demonstrated to stakeholders. The post closure plan for OK Tedi considers: closure criteria, post closure monitoring and post closure maintenance.

\subsubsection{Closure criteria}

OTML have developed robust and defensible closure criteria as a tool to demonstrate closure performance and have linked these to the lease relinquishment process. OTML established a dedicated project team comprising OTML staff and expert consultants, to debate and develop closure criteria for Ok Tedi. The OTML closure criteria framework consists of aspects, objectives, criteria and standards. These relate to each other as follows:

- Aspects - are elements that need to be considered for closure of every area and that together will ensure the overall closure objective is addressed.

- Objectives - describe the intent of the mine closure program in relation to each aspect.

- Criteria - describe specific elements that can be measured or certified to have occurred, and that are considered to be critical to achieving the objective.

- Standards - may be either an agreed value that is measurable and is regarded as the minimum that must be achieved, or a certification that specific closure activities comply with an agreed plan for those activities.

In line with ANZMEC \& MCA (2000) Ok Tedi closure criteria are site specific and cover a range of aspects. Once OTML have met the agreed closure criteria, the State will accept that closure risks have been reduced sufficiently and allow OTML to relinquish their leases.

\subsubsection{Post closure monitoring}

OTML will undertake post closure monitoring to measure performance against closure objectives in operational areas, and will also measure the long-term impacts to the river system. OTML have made provision for US\$ 39.1 million in their closure cost estimate to fund post closure environmental and social monitoring for up to thirty years after mine closure.

\subsubsection{Post closure maintenance}

After closure and rehabilitation works are complete, rehabilitated areas will be maintained by OTML until machinery are demobilised from site. The requirement for active maintenance of rehabilitated areas will diminish with time, as vegetation establishes and helps to minimise erosion.

Two endowment funds will be established to provide for basic long-term security and maintenance of key areas beyond the OTML maintenance period and after lease relinquishment. The endowment funds will be held in perpetuity. Provision has been made for both endowment funds within the closure cost estimate. One fund will be for the mine area clans and the second will be for the Bige area clans. The size of each fund has been calculated so that a number of members from each clan are paid a wage in return for providing basic security and maintenance of each area.

The procedure for disbursements from these funds will involve annual checks to ensure that the clans have been managing the land in accordance with the purpose of the funds. If the land has not been managed appropriately disbursements will not be made. It is proposed that the clan members to be involved in this 
scheme will also be involved in closure and rehabilitation planning and implementation. The participants will therefore have the skills and knowledge to enable the concept to be effective. A similar program has been successfully implemented at the Kelian Mine.

\subsection{Social and economic impacts of closure}

In 2008 a standalone project team comprising OTML staff, expert consultants and external stakeholders, was established to develop a Social and Economic Report (SER) on the social and economic impacts of mine closure, and the status of social and economic programs being undertaken by OTML and other stakeholders in Western Province to mitigate these impacts. The aim of the SER was to help key stakeholders identify opportunities to enhance long term development outcomes and minimise negative impacts from mine closure.

Prior to development of the SER a literature review was undertaken to assess existing mine closure guidelines and draw on recent mine closure experience, in particular those aspects relating to the compilation of social and economic data. It was found however that environmental factors continue to dominate mine closure planning efforts in developed countries such as Australia and the USA. Relatively few large-scale mines have closed in recent years, and even fewer provide lessons that can be applied to the closure of Ok Tedi.

The SER was compiled in open consultation with stakeholders, and large parts of the report were developed in workshops attended by the Planning Committee. The format of the SER, as agreed by the Planning Committee, included:

- Identify target/impacted groups and key stakeholders.

- Describe the current status of target groups.

- Predict the impact of mine closure on target groups.

- Include stakeholder concepts for alternative economic activities in the Western Province after mine closure.

- Summarise the development strategies of key stakeholders aimed at minimising closure impacts on target groups.

- Develop recommendations to minimise the social and economic impacts from mine closure on target groups.

Two substantial bodies of work were completed to assist in the development of the SER, particularly in the description of the current status of target groups. The first was the 'impact area profiles' (IAP) which presents social and economic data for those communities directly impacted by the Ok Tedi mine. The primary source of data for the IAP was a population census conducted by OTML in late 2007, which surveyed 138 villages and 12,351 households with a population of 88,806 people. The IAP also utilise a wide range of other current and historical data sources, to provide comparisons over time to the Western Province or to PNG as a whole. The IAP provides useful information to development partners, to assist them in planning and implementing programs to mitigate closure impacts on the communities.

The second body of work was a 'benefit stream analysis' (BSA) which provides: an estimate of mine benefits and their distribution since mining commenced; an estimate of future benefits and their distribution until mine closure and; an estimate of the mine-related benefits available after mine closure.

The recommendations of the SER are currently being implemented by OTML and their stakeholders; the SER was designed to be accessible to and used by all relevant stakeholders.

\subsection{Closure cost estimation}

The risk of underestimating closure costs is that insufficient funds will be available to finance mine closure. The Mine Closure and Decommissioning Code 2001 requires that OTML specify the amount of 'financial 
assurance' necessary for the performance of the mine closure plan and provide a copy of a statement of an independent person approved by the State and qualified to make it, that the estimate of the cost of completing the mine closure plan is reasonable.

The Code also requires that OTML establish a reserve account in the joint names of the Company and the State to be known as the Ok Tedi Financial Assurance Fund (FAF) to which monies are contributed by way of financial assurance. The size of the contributions to the FAF are such that, when taken together with interest accruing on those contributions, by the estimated date of closure there will be adequate amounts in the fund to implement the mine closure plan.

A dedicated project team was established to compile a detailed closure cost estimate. Expert consultants were also engaged to assist in estimating asset realisation, deconstruction and logistics costs. The estimate includes costs for deconstruction and removal of infrastructure and equipment, engineering and landform works, and revegetation works. The estimate also includes costs for redundancies, post closure monitoring, six months of dredging after closure, risk mitigation, risk based contingency, project contingency and escalation. The current closure cost estimate is US\$227.5 million, a figure which has been endorsed by independent auditors appointed on behalf of the State.

\section{Conclusions}

OTML have adopted a risk based approach to guide progressive closure planning for Ok Tedi. Quantification and modelling of risks has enabled OTML to estimate risk cost and to develop a risk mitigation strategy, and to include within their closure cost estimate a risk mitigation allowance and a risk based contingency allowance. A major achievement of the risk process is that external stakeholders are now considering what role they will play in mitigating residual risks and are collaborating on joint studies to assess residual risks in further detail.

More broadly, OTML and their stakeholders have integrated risk assessment outcomes into the closure planning process to help define and prioritise closure planning initiatives; all of which will enhance the closure outcomes for Ok Ted.

\section{References}

ANZMEC \& MCA (2000) Strategic Framework for Mine Closure. National Library of Australia Catalogue Data.

Bentley, K. (2007a) OTML Community Health Study (CHS), Volume 1: Design, conduct and analysis of the OTML CHS food and nutrition studies including: twenty four-hour dietary recall food frequency survey, unit (individual) food consumption contaminant and essential metals market basket survey and nutritional anthropometrics, An unpublished report prepared by Centre for Environmental Health Pty Ltd and submitted to Ok Tedi Mining Limited, dated May 2007, 112 p. (plus appendices).

Bentley, K. (2007b) OTML Community Health Study (CHS), Volume 2: Health Status in the Ok Tedi-Fly Rivers communities hazard and exposure assessment and risk characterisation and risk analysis, An unpublished report prepared by Centre for Environmental Health Pty Ltd and submitted to Ok Tedi Mining Limited, dated May 2007, 132 p. (plus appendices).

Bowben, A.R., Lane, M.R. and Martin, J.H. (2001) Triple Bottom Line Risk Management, Enhancing Profit, Environmental Performance and Community Benefits, Wiley.

Higgins, R.J., Pickup, G. and Cloke, P.S. (1987) Estimating the transport and deposition of mining waste at Ok Tedi, C.R. Thorne, J.C. Bathurst and R.D. Hey (eds), Sediment Transport in Gravel Beds, Wiley, Chichester, pp. 946-976.

Moi, A.S., Dremdap, T. and Simbina, P. (2001) APL Compliance and Additional Monitoring Program 1999/2000 Annual Report, Appendix 1 - Hydrology, An unpublished report (Report ENV0-02) prepared by Ok Tedi Mining Limited's Environment Department and submitted to the State of PNG.

Pickup, G. (2009) Geomorphology, hydrology and climate of the Fly River system, B.R. Bolton (ed), The Fly River Papua New Guinea Environmental Studies in an Impacted Tropical River System, Developments in Earth \& Environmental Sciences, 9. Elsevier, Amsterdam, pp. 3-49.

Storey, A.W., Marshall, A.R. and Yarrao, M. (2009) Effects of mine derived river bed aggradation on fish habitat of the Fly River, Papua New Guinea, B.R. Bolton (ed), The Fly River Papua New Guinea Environmental Studies in an Impacted Tropical River System, Developments in Earth \& Environmental Sciences, 9. Elsevier, Amsterdam, pp. 463-490.

Swales, S., Storey, A.W. and Bakowa, K.A. (2000) Temporal and spatial variations in fish catches in the Fly River system in Papua New Guinea and the possible effects of the Ok Tedi copper mine, Environmental Fish Biology, 57, pp. 75-95. 